Cite this article as: Dalton, T.M. \& Jin, D. Environmental Management (2018) 61: 848.

\title{
Attitudinal factors and personal characteristics influence support for shelfish aquaculture in Rhode Island (US) coastal waters
}

\author{
Tracey M. Dalton \\ Department of Marine Affairs \\ University of Rhode Island \\ Kingston, RI 02881 USA \\ Corresponding author: \\ Tel: +1 $401874-2434$ \\ Email: dalton@uri.edu

\section{Di Jin} \\ Marine Policy Center \\ Woods Hole Oceanographic Institution \\ Woods Hole, MA 02543 USA
}

\begin{abstract}
This study explores public interests associated with shellfish aquaculture development in coastal waters of Rhode Island (US). Specifically, we examine (1) the levels of public support for (or opposition to) shellfish aquaculture development and (2) factors driving the levels of support, using survey data and ordinal logistic regressions. Results of the analysis identify several key attitudinal factors affecting individual's support for shellfish aquaculture in Rhode Island (RI). The level of support is positively associated with attitudes related to shellfish aquaculture's benefits to the local economy and its role as a nutritional food option, and negatively influenced by attitudes related to aquaculture farms' effects on aesthetic quality and their interference with other uses. Findings highlight that support for (or opposition to) aquaculture in RI is driven more by attitudes associated with social impacts than by those associated with environmental impacts. The level of support is also affected by personal characteristics related to an individual's participation in recreational activities. For instance, bicycle riders tend to be supportive of shellfish aquaculture while respondents who participate in sailing and birding are less supportive. By identifying the broader public's interests in shellfish aquaculture, findings from this study and others like it can be used to address public concerns, incorporate public perceptions and attitudes into permitting decisions, and develop outreach targeted at specific stakeholder groups.
\end{abstract}

Keywords: aquaculture; shellfish; public interest; environmentally-significant behavior

Acknowledgements: We thank Joseph Dwyer, Allie Katzanek, Sarina Lyon, and Maria Vasta for help with data collection. This research was funded by the Rhode Island Sea Grant [NA14OAR4170082] with additional support from the URI College of Environment and Life Sciences and the Marine Policy Center at the Woods Hole Oceanographic Institution. 


\section{Attitudinal factors and personal characteristics influence support for shellfish aquaculture in Rhode Island (US) coastal waters}

\section{INTRODUCTION}

Aquaculture development has been considered as a potentially effective solution to meet growing demand for seafood and for reducing trade deficit in the United States. However, the growth of aquaculture has been hampered by concerns for the environment, user conflicts in crowded near-shore waters, and inefficiencies in the regulatory system (Kite-Powell et al. 2013; Knapp and Rubino 2016; NOAA 2008). In the state of Rhode Island (RI), the number of aquaculture farms has been steadily increasing, from five farms in 1995 to 70 in 2016 with sales over \$5.5 million (Beutel 2016) (Figure 1). In contrast, due to stock depletion and changing marine resource conditions, the traditionally important commercial fishing industry has been in contraction with total landings reduced from over 60 thousand metric tons (MTs) in the 1990s to 34 thousand MTs (valued at $\$ 82$ million) in 2015 (NOAA 2017; Jin et al. 2016).

RI state law mandates that aquaculture be conducted in a manner consistent with the best public interest (RI GL 20-10), where the public interest includes the desires and needs of society (Birkland 2001). As policy scientists have noted over the years, the public interest is highly dependent on the people defining it. Conflicts emerge because there is usually no agreement on one single public interest (Birkland 2001). The agency charged with permitting and regulating aquaculture in the state of RI (Coastal Resources Management Council, CRMC) must first understand the different public interests within the state, and then reconcile them to make permitting decisions. This study explores public interests associated with shellfish aquaculture development in RI's coastal waters. 


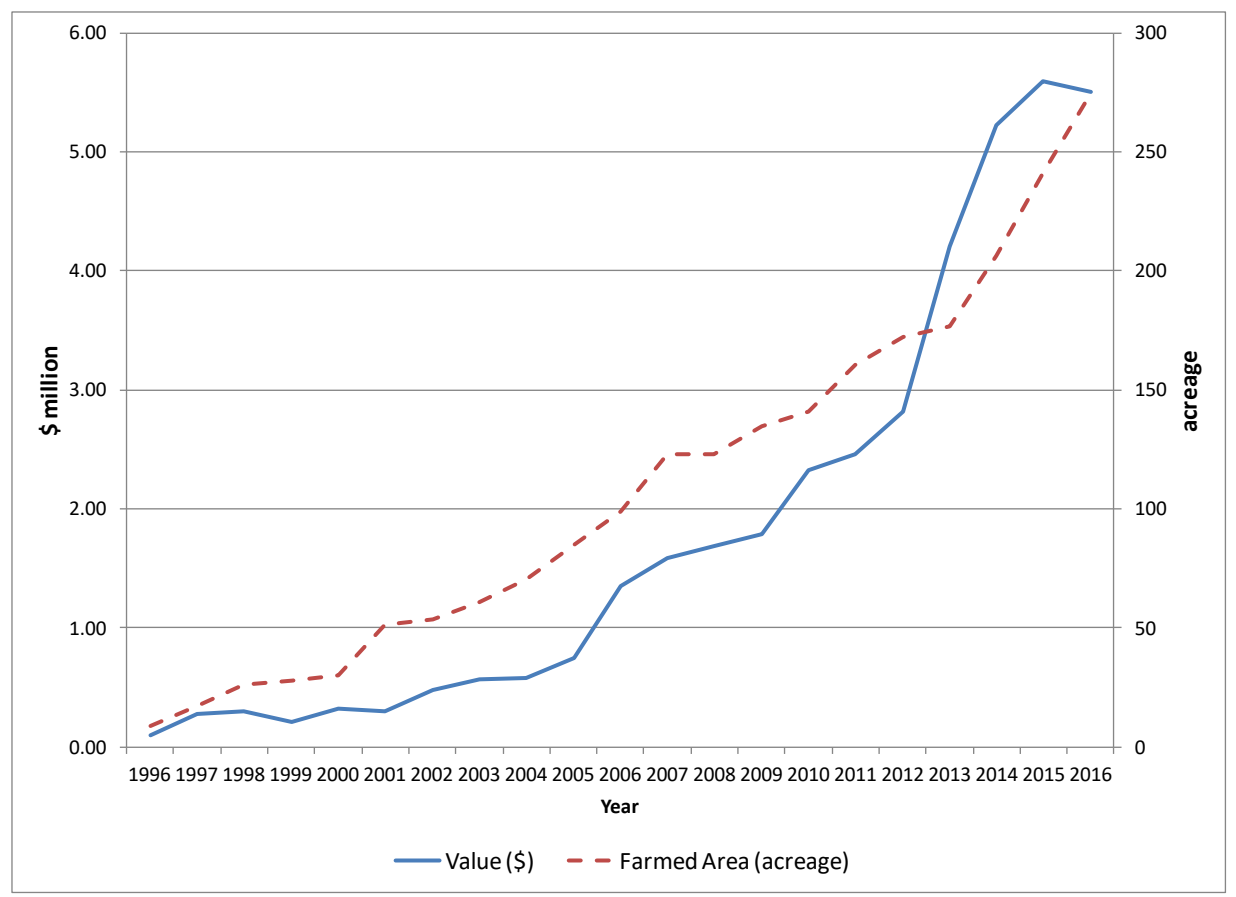

Figure 1. Aquaculture Output Value and Farmed Area in Rhode Island

The RI CRMC gathers some information on the public's concerns and interests during the regulatory review process for proposed aquaculture projects. All proposed aquaculture projects must first go through a preliminary determination review where towns, various state agencies (e.g., Department of Health, Department of Environmental Management), and other stakeholders can comment on the proposal (RI CMP 300.11). While this process can provide important opportunities for RI CRMC and other agencies to hear some of the views of the public, it likely captures the views of a subset of the RI general public consisting of those individuals that are more likely to become engaged in the process (e.g., Voyer et al. 2012). To reveal broader public interests, it is necessary to complement public meetings with other techniques capable of sampling the general population (Voyer et al. 2012). Social science methods from an array of disciplines can be used to systematically collect data on what people are doing and how people think about these various activities (Vaske 2008). This study builds on prior work in social 
psychology, environmental resource management, and sociology to examine (1) levels of public support for (or opposition to) shellfish aquaculture development in Rhode Island and (2) the factors that affect levels of support for (or opposition to) shellfish aquaculture projects in Rhode Island.

\subsection{Modeling environmentally-significant behavior}

Choices that people make related to transportation, energy use, water and food can have significant environmental impacts (NRC 2005). Stern (2000) developed a framework for understanding internal motivations and external conditions that influence these choices, or environmentally-significant behaviors (ESBs). Although the model has typically been applied to household energy use (e.g., Steg et al. 2005) and recycling behaviors (e.g., Guagnano et al. 1995), it provides a framework within which other environmental decisions can be framed (Wilson and Dowlatabadi 2007), such as an individual's decision to support (or oppose) a shellfish aquaculture project. Choices about where to site shellfish aquaculture activities and how much shellfish aquaculture to allow in a particular waterbody will have environmental effects. For instance, shellfish aquaculture activities have the potential to impact a variety of features in the natural environment, such as coastal nutrient dynamics, oxygen in the water column, phytoplankton, and organic enrichment of sediment (Filgueira et al. 2015; Cranford et al. 2012). In Stern's (2000) model, these choices, or ESB, are influenced by different types of causal variables such as attitudinal factors, personal characteristics and external conditions.

Attitudinal factors comprise the values, beliefs, attitudes and norms that influence an individual's predisposition to behave in an environmentally-significant manner and actual behavior (Stern 2000). Values are single, stable beliefs that transcend objects or situations 
(Heberlein 1981) and act as guiding principles in life (Stern et al. 1995). Attitudes are generally defined as the tendency to respond favorably or unfavorably toward an object (Vaske and Donnelly 1999). Belief has been described as acceptance without rigorous evidence (Aiken 2002), and norms are defined as rules to direct behavior that involve a sense of obligation and sanctions for non-compliance (Coleman 1990; Heberlein 2012; Ostrom 1990). ESBs are most strongly influenced by attitudinal factors that are most specific to the behavior (e.g., Kaiser et al. 1999; Kraus 1995; Steel 1996).

Personal characteristics such as an individual's social status, literacy, knowledge, availability of time to act, money, social status and power, age, educational attainment, race, and income have been found to affect environmental concern and behavior (e.g., Hines et al. 1986/87; Olli et al. 2001; Steel 1996; Stern 2000; Stern and Dietz 1994).

External conditions, or contextual factors, include social, financial, legal, and physical features of an individual's surroundings (Guagnano et al. 1995). For instance, social conditions include persuasion, personal commitments, community expectations, and interpersonal influences. Other features include laws and regulations, technology, private contracts, financial costs and rewards, convenience, various economic and political features (Stern 2000), and participation in different organizations and networks (Olli et al. 2001).

\subsection{Modeling support for aquaculture}

Stern's model provides a general framework within which to frame more specific hypotheses guided by theory, empirical research and practical experience related to aquaculture (Figure 2). Recent studies have addressed some of the features of Stern's model, but there has been no systematic, comprehensive study of these factors to identify those that are having the greatest 
influence on an individual's decision to support aquaculture so that management efforts can be directed at those key features.

Past studies of attitudinal factors related to aquaculture tend to focus on perceived impacts on

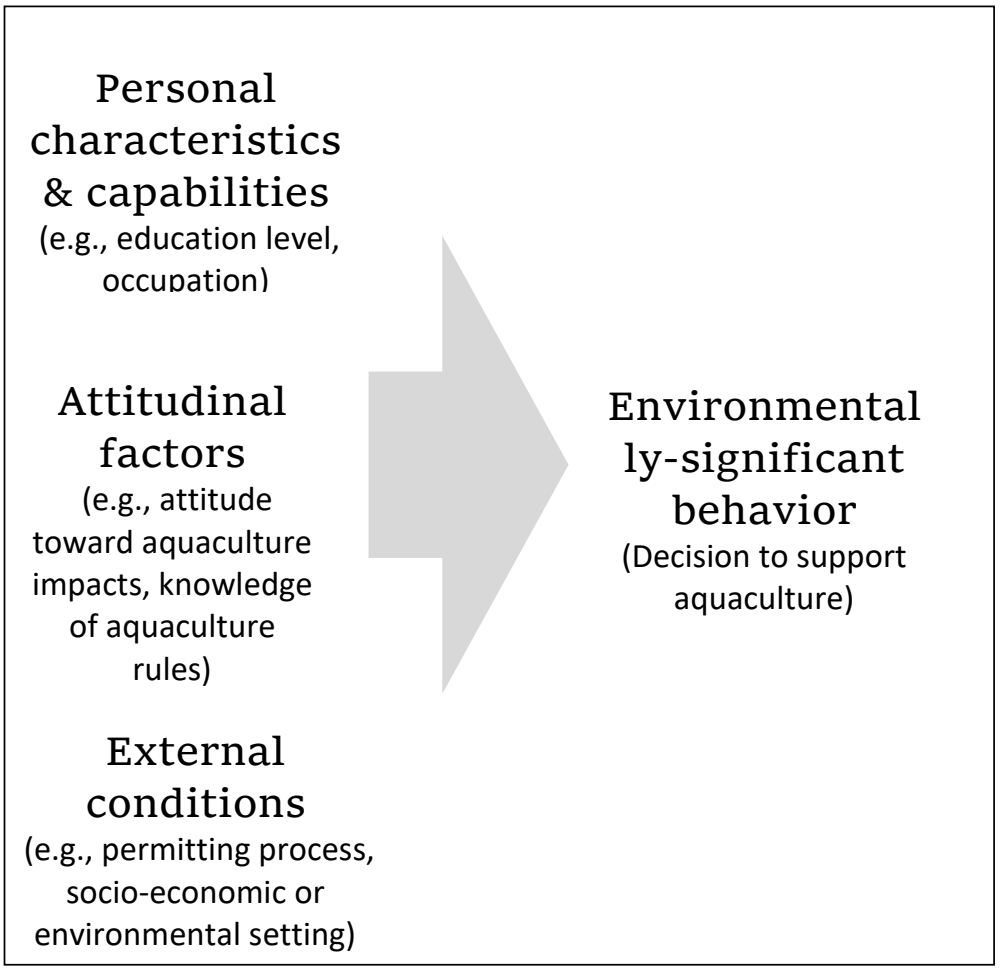

Figure 2. Model of factors influencing an individual's decision to support aquaculture the environment, the local

economy, and existing (potentially

displaced) uses. Katranidis et al.

(2003) found that survey

respondents from two islands in

Greece tended to think that

aquaculture would not have many

negative impacts, but it would lead

to more jobs. In a mail survey in

coastal regions of Australia, Mazur

and Curtis (2008) found that

respondents' perceptions of

government agencies related to aquaculture influenced how they felt about aquaculture projects.

Findings from a mail survey of Scotland coastal residents indicate that public attitudes toward the future of salmon farming are related to their perceived environmental and economic impacts (Whitmarsh and Palmieri 2009). In a survey of aquaculture stakeholders in the US and Norway, Chu et al. (2010) found that perceptions of economic and ecological impacts of aquaculture contributed to an individual's support for aquaculture expansion. Joyce and Satterfield (2010) found that concerns about shellfish farming in British Columbia, Canada were related to stakeholders' perceptions about the risk of aquaculture to their way of life mainly due to a loss of 
access to wild fisheries. In a recent study of shellfish aquaculture in British Columbia, D'Anna and Murray (2015) found that most respondents felt positively about the effects of shellfish aquaculture on the economy and negatively or uncertain about its environmental effects, and they did not agree on how shellfish aquaculture affected their lived experience (i.e. aesthetics, social experiences, surrounding environment).

Personal characteristics, like age, gender, education, and participation in certain activities, have been found to have some effect on perceptions of and support for aquaculture (e.g., Katranidis et al., 2003; Mazur and Curtis, 2008; Murray and D'Anna, 2015; Shafer et al. 2010).

External conditions, including the social, financial, legal, and physical features of an individual's surrounding, are considered important to Stern's ESB framework but have gotten limited attention in studies of public perceptions of and support for aquaculture. Such factors could include the regulatory structure for managing aquaculture which varies by state (and sometimes by town) in the US, the socioeconomic conditions of a particular community, or the environmental setting where an aquaculture site is proposed (e.g., site with high density development or a pristine environment). Property rights and historical uses of coastal waters and adjacent lands could also affect participation in and support for the shellfish aquaculture industry (e.g., Silver 2013; Silver 2014).

Additional factors that could influence support for (or opposition to) aquaculture include limited public knowledge of the leasing process, type of aquaculture method proposed, proximity of residence to shoreline, and perception that aquaculture competes with wild harvest fisheries. 


\section{METHODS}

To investigate public support for shellfish aquaculture in RI's coastal waters and the factors influencing it, we conducted a mail survey in Rhode Island in the spring and summer 2015. Mail surveys are a useful way to reach a large sample of dispersed individuals, such as residents of multiple coastal communities throughout a particular area (Dillman et al. 2009). Additional strengths of mail surveys include (1) flexibility for respondents to think over their answers; (2) assurance of respondent anonymity; and (3) greater probability that respondents will not provide answers that they think an interviewer would want to hear (Vaske 2008). The survey data were analyzed using regression models to provide a deeper understanding of the drivers affecting public support for aquaculture.

Rhode Island provides an ideal setting for this study because aquaculture has been going on in state waters for over one hundred years and the state has a history of intense public reaction to shellfish aquaculture projects. In addition, the state of Rhode Island recently led a process to develop a comprehensive Shellfish Management Plan to guide decisions about shellfish harvesting, restoration, and aquaculture in Rhode Island's waters (RI CRMC 2014). We focus on bivalve shellfish because the American oyster is the primary aquaculture product in RI, with some limited production of hard clams and mussels. The aquaculture industry in RI, with over 170 employees working at 70 farms throughout the state, has steadily increased since 1996 (Beutel 2016).

\subsection{Data collection}

We used stratified random sampling to mail the survey to residents in three regions in RI: south coast, Narragansett Bay, and inland (Figure 3). Mailing addresses for individuals living in 
RI were obtained from a company specializing in residential database management. We mailed 320 surveys to randomly selected addresses in each of the three regions. To ensure that certain affected groups would be represented in our sample, we also mailed the survey to 340 waterfront residents (170 in the south coast; 170 in Narragansett Bay). We followed Dillman et al.'s (2009) tailored design method by first sending out a cover letter with each survey and a stamped self-addressed envelope. We then sent a reminder postcard after three weeks and a second round of surveys after that. We also distributed 48 surveys to marinas and wild harvest shellfish dealers and mailed out 29 surveys to shellfish farmers. In total, we distributed 1288 surveys ( 89 mail surveys were returned as undeliverable) and received 272 completed surveys for a response rate of $21 \%$.

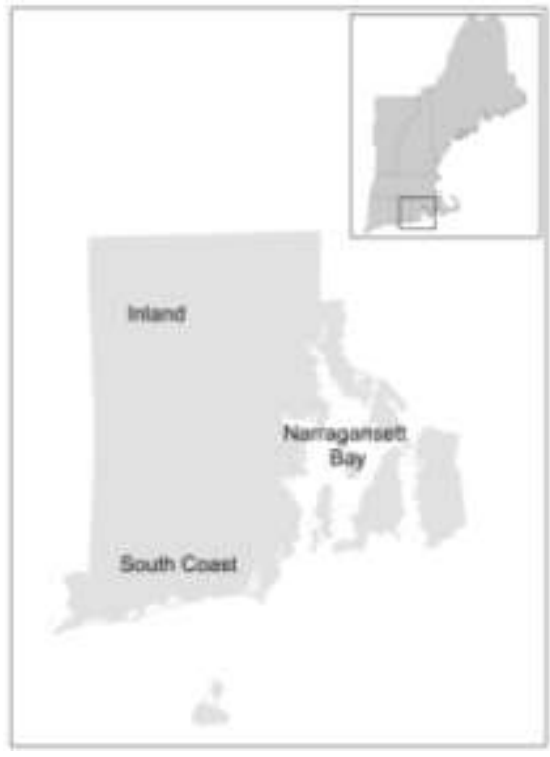

Figure 3. Three regions in Rhode Island (inset: New England states with study area)

The survey instrument elicited data on factors that could influence an individual's decision to support aquaculture in RI's coastal waters. Narrative questions asked respondents about their attitudes related to shellfish aquaculture impacts on the natural environment (pollutes the water; improves water quality) and on humans (good for the economy; important part of the cultural landscape; spoils environmental beauty; makes the scenery more pleasing; supports nutritional needs; negatively impacts navigation; enhances experience of nearby users; generates too much noise; displaces wild harvest shellfishermen; reduces environmental pressures from wild harvest shellfishing; interferes with other uses). Questions also asked about attitudes toward aquaculture in RI (planning and permitting decisions are important to the respondent; permitting process 
allows for adequate public involvement; lease fees for aquaculture are appropriate; there should be more or less aquaculture in RI) and knowledge of aquaculture in RI (respondent knows the responsible regulatory agency and type of fish farmed in RI waters). Respondents were also asked about their personal characteristics (visibility of shoreline from their home; types of uses in and around RI's coastal waters; participation in management activities; education; age) and external conditions (region of residence). We also asked respondents to state their level of agreement on a 5-point scale ( $1=$ strongly disagree to $5=$ strongly agree) with the statement $I$ support shellfish aquaculture in RI coastal waters. To ensure that survey questions captured issues and concerns relevant to shellfish aquaculture in RI, we pre-tested and refined the surveys with various stakeholders, including wild harvest fishermen, shellfish aquaculture farmers, members of coastal neighborhood associations, other RI residents, and coastal managers.

\subsection{Model}

As noted above, the response to our survey question to gauge public support for shellfish aquaculture in RI coastal waters is not dichotomous (yes/no). Each respondent specified a level of support on a 5-point scale, and thus the response captures both direction (yes/no) and intensity of attitude. To examine the effects of different factors on an ordinal response variable $(y)$, researchers typically use ordinal logistic regression models (detailed in the appendix). Specifically, in the survey data set, $y$ has five entries, taking on the value of $1,2, \ldots, 5: y=1$, if the respondent strongly opposes shellfish aquaculture; $y=3$, if the respondent is indifferent about shellfish aquaculture; and $y=5$, if the respondent strongly supports shellfish aquaculture. The purpose of the regression analysis is to investigate how well that ordinal response $(y)$ can be predicted by the responses to other questions on the survey. The ordinal logistic regression 
model is based on the proportional odds assumption which suggests that the coefficients that describe the relationship between, say, the lowest versus all higher categories of the response variable $(y)$ are the same as those that describe the relationship between the next lowest category and all higher categories (e.g., $y=1$ vs $y=2$ is the same as $y=4$ vs $y=5$ ).

The survey data include a wide range of attitudinal factors, personal characteristics and external condition variables. To identify key drivers of the response variable (support for shellfish aquaculture in RI coastal waters), all variables were evaluated using a combination of manual specification of different models and stepwise regression models. The model selection procedure produced two models reported below. Model I is parsimonious, and Model II includes a wider set of variables significantly affecting the level of support for shellfish aquaculture in RI coastal waters.

\section{RESULTS}

The primary residence for most respondents was in RI, with $42 \%$ living along the southern coast, $42 \%$ from communities bordering Narragansett Bay, $12 \%$ from inland communities, and the rest from out-of-state or chose not to answer this question. Three percent of respondents were shellfish farmers, four percent were wild harvest shellfishermen, and 38\% percent of the sample indicated that they were retired. Over half the respondents had Bachelor's degrees and earned more than $\$ 75,000$ per year in household income. Eighty-seven percent of respondents said they participate in recreational activities along RI's shoreline or in its coastal waterways. Most popular activities for those indicating they participate in coastal recreation include walking along the shoreline (70\%), relaxing (69\%), hook and line fishing (41\%), motor 
boating (46\%), bicycle riding (37\%), paddling (36\%), harvesting shellfish (32\%), birding (20\%), and sailing (19\%).

There were 269 observations with full information on the response variable. A small number of missing values in the explanatory variables were replaced with relevant sample means. Variables used in the estimation of support for shellfish aquaculture in Rhode Island's coastal waters, their definitions, and descriptive statistics (mean, standard deviation, minimum and maximum values) appear in Table 1.

The mean for the dependent variable, support for aquaculture in RI waters $(y)$, is 3.98 , close to 4 (agree with the statement I support shellfish aquaculture in RI coastal waters). Among the respondents, $32 \%$ strongly agreed with the statement $(y=5), 46 \%$ agree $(y=4), 13 \%$ neither agree nor disagree $(y=3), 4 \%$ disagree $(y=2)$, and $4 \%$ strongly disagree $(y=1)$. The mean statistics for the explanatory variables reveal that, on average, respondents agree that shellfish aquaculture is good for Rhode Island's economy (mean of economy $=4.17$ ) and are not certain that aquaculture interferes with other uses. The average education level is 5.39 (with some college education). Of the respondents, $20 \%$ participate in birding, 37\% participate in bicycle riding, and 19\% sail in RI's coastal waters. Forty-three percent of the respondents' homes, including year-round and seasonal residences, have a view of coastal waters.

Table 2 reports the results from two ordered logit models for the $y^{*}$ in equation (1) in the appendix using the survey data. The table includes results for statistically significant explanatory variables and constant terms. The likelihood ratio tests for both models are statistically significant at the 0.01 level. Model I has good properties (i.e., being parsimonious and consistent with the proportional odds assumption). Model II offers additional information on a wider set of explanatory variables. The estimation results of Model I suggest that, among variables describing 
Table 1. Variable Definitions and Descriptive Statistics

\begin{tabular}{|c|c|c|c|c|c|}
\hline Variable & Definition & Mean & Std Dev & Min & Max \\
\hline \multicolumn{6}{|c|}{ Dependent Variable } \\
\hline Support & $\begin{array}{l}\text { Support aquaculture in RI waters } \\
\text { ( } 1=\text { strongly disagree; } 5=\text { strongly agree) }\end{array}$ & 3.978 & 1.011 & 1 & 5 \\
\hline \multicolumn{6}{|c|}{ Explanatory Variables } \\
\hline \multicolumn{6}{|l|}{ Attitudinal factors } \\
\hline Economy & $\begin{array}{l}\text { Aquaculture is good for economy } \\
\text { ( } 1=\text { strongly disagree; } 5=\text { strongly agree) }\end{array}$ & 4.165 & 0.912 & 1 & 5 \\
\hline Spoil beauty & $\begin{array}{l}\text { Aquaculture spoils environmental beauty } \\
\text { (1=strongly disagree; } 5=\text { strongly agree) }\end{array}$ & 2.698 & 1.197 & 1 & 5 \\
\hline Nutrition supply & $\begin{array}{l}\text { Aquaculture supports nutritional needs } \\
\text { ( } 1=\text { strongly disagree; } 5=\text { strongly agree) }\end{array}$ & 3.701 & 0.974 & 1 & 5 \\
\hline Interfere use & $\begin{array}{l}\text { Aquaculture interferes with other uses } \\
\text { ( } 1=\text { strongly disagree; } 5=\text { strongly agree) }\end{array}$ & 2.876 & 1.101 & 1 & 5 \\
\hline Important & $\begin{array}{l}\text { Planning and permitting decisions are } \\
\text { important to me ( } 1=\text { strongly disagree; } \\
5=\text { strongly agree) }\end{array}$ & 4.062 & 0.813 & 1 & 5 \\
\hline Need more & $\begin{array}{l}\text { There should be more aquaculture in RI } \\
\text { ( } 1=\text { strongly disagree; } 5=\text { strongly agree) }\end{array}$ & 3.473 & 1.127 & 1 & 5 \\
\hline \multicolumn{6}{|c|}{ Personal Characteristics } \\
\hline Shore visible & $\begin{array}{l}\text { Can see shoreline from home }(1=y e s ; \\
0=\text { no) }\end{array}$ & 0.431 & 0.496 & 0 & 1 \\
\hline Sailing & Sailing in coastal waters $(1=\mathrm{yes} ; 0=$ no $)$ & 0.194 & 0.395 & 0 & 1 \\
\hline Birding & Birding in coastal area $(1=\mathrm{yes} ; 0=\mathrm{no})$ & 0.201 & 0.401 & 0 & 1 \\
\hline Biking & Biking in coastal area $(1=$ yes; $0=$ no $)$ & 0.373 & 0.484 & 0 & 1 \\
\hline Meeting & $\begin{array}{l}\text { Attended aquaculture planning meeting } \\
(1=\text { yes; } 0=\text { no })\end{array}$ & 0.105 & 0.306 & 0 & 1 \\
\hline Education & $\begin{array}{l}\text { Education level (1=less than high school; } \\
7=\text { graduate or advanced degree) }\end{array}$ & 5.392 & 1.535 & 1 & 7 \\
\hline
\end{tabular}


Table 2. Support of Shellfish Aquaculture: Ordered Logit Estimates

\begin{tabular}{|c|c|c|}
\hline Variable & $\begin{array}{l}\text { Model I } \\
\text { Coefficient } \\
\text { (standard error) }\end{array}$ & $\begin{array}{l}\text { Model II } \\
\text { Coefficient } \\
\text { (standard error) }\end{array}$ \\
\hline Intercept 5 & $\begin{array}{l}-13.0906^{* * *} \\
(1.6818)\end{array}$ & $\begin{array}{l}-16.4780^{* * * *} \\
(2.0679)\end{array}$ \\
\hline Intercept 4 & $\begin{array}{l}-8.2555^{* * * *} \\
(1.5281)\end{array}$ & $\begin{array}{l}-11.1116^{* * * *} \\
(1.8267)\end{array}$ \\
\hline Intercept 3 & $\begin{array}{l}-5.0069^{* * *} \\
(1.4309)\end{array}$ & $\begin{array}{l}-7.8978^{* * *} \\
(1.7113)\end{array}$ \\
\hline Intercept 2 & $\begin{array}{l}-2.8090^{* *} \\
(1.3633)\end{array}$ & $\begin{array}{l}-5.8266^{* * *} \\
(1.6594)\end{array}$ \\
\hline Economy & $\begin{array}{l}2.2133^{* * *} \\
(0.2932)\end{array}$ & $\begin{array}{l}2.1468^{* * * *} \\
(0.3037)\end{array}$ \\
\hline Spoil beauty & $\begin{array}{l}-0.6549^{* * *} \\
(0.1636)\end{array}$ & $\begin{array}{l}-0.6023^{* * *} \\
(0.1707)\end{array}$ \\
\hline Nutrition supply & $\begin{array}{l}0.9628^{* * *} \\
(0.2219)\end{array}$ & $\begin{array}{l}0.7498^{* * *} \\
(0.2388)\end{array}$ \\
\hline Interfere use & $\begin{array}{l}-0.5176^{* * *} \\
(0.1665)\end{array}$ & $\begin{array}{l}-0.5470^{* * *} \\
(0.1753)\end{array}$ \\
\hline Important & - & $\begin{array}{l}0.5042^{* *} \\
(0.2084)\end{array}$ \\
\hline Need more & - & $\begin{array}{l}0.5813^{* * *} \\
(0.2064)\end{array}$ \\
\hline Shore visible & $\begin{array}{l}0.5620^{*} \\
(0.3176)\end{array}$ & $\begin{array}{l}0.5695^{*} \\
(0.3437)\end{array}$ \\
\hline Sailing & - & $\begin{array}{l}-0.8867^{\text {*** }} \\
(0.4254)\end{array}$ \\
\hline Birding & $\begin{array}{l}-0.8207^{* *} \\
(0.3841)\end{array}$ & $\begin{array}{l}-0.7950^{*} \\
(0.4078)\end{array}$ \\
\hline Biking & $\begin{array}{l}0.7989^{* *} \\
(0.3359)\end{array}$ & $\begin{array}{l}1.0119^{\text {**** }} \\
(0.3535)\end{array}$ \\
\hline Meeting & - & $\begin{array}{l}1.0081^{*} \\
(0.5759)\end{array}$ \\
\hline Education & $\begin{array}{l}0.1961^{*} \\
(0.1012)\end{array}$ & $\begin{array}{l}0.2208^{* *} \\
(0.1041)\end{array}$ \\
\hline Observations & 269 & 269 \\
\hline $\mathrm{R}^{2}$ & 0.784 & 0.804 \\
\hline Likelihood ratio test & $342.82^{* * *}$ & $361.65^{* * * *}$ \\
\hline
\end{tabular}

$*$, ** and *** denote significance at 10, 5, 1\% significance level, respectively. The sorting order of response variable (support) is reversed ( $1=$ strongly agree; $5=$ strongly disagree) in model estimations to accommodate the default setting of SAS Logistic Procedure, as reflected in the signs and magnitudes of intercept coefficients. 
a respondent's attitudes toward shellfish aquaculture, the level of support is positively related to economy and nutrition supply and negatively related to spoils beauty and interferes with use. Thus, the support is greater if the respondent thinks that shellfish aquaculture is good for Rhode Island's economy and will provide a healthy option for meeting people's nutritional needs. The support is expected to be lower, and opposition stronger, if the respondent thinks that shellfish aquaculture spoils the beauty of the coastal environment and interferes with other uses.

The model results for personal characteristics variables suggest the level of support is expected to be greater if the respondent's home has a coastal water view (although the shore visible variable is marginally significant), the respondent's recreational activities include bicycle riding, and the respondent has a higher level of education. In contrast, lower support is expected if the respondent's recreational activities include birding.

Model II includes additional explanatory variables that are statistically significant, including two attitudinal factors related to aquaculture in RI (important and need more in RI) and two describing personal characteristics (sailing and meeting). The model results suggest that positive relationships exist between the level of support for shellfish aquaculture in RI and the view that planning and permitting decisions about aquaculture are important, between support and the view that there should be more aquaculture in RI, and between support and the fact that the respondent has attended at least one public meeting related to shellfish or aquaculture planning or management. In contrast, a respondent who participates in sailing is expected to have a lower level of support for aquaculture. As to the rest of the explanatory variables, estimation results of Model II are consistent with those of Model I.

The coefficients of Model I indicate that for a 1-unit increase in the economy variable (i.e., going from 1 to 2 on the 5-point scale), we expect a 2.21 increase in the log odds of being in a 
higher level of support for shellfish aquaculture in RI coastal waters, given all of the other variables in the model are held constant. For a respondent who participates in birding, we would expect a 0.82 decrease in the log odds of being in a higher level of support for shellfish aquaculture in RI coastal waters.

The model estimation results can be used to calculate the predicted probabilities using equation (6) in the appendix. For example, the predicted probabilities were calculated at economy $=1, \ldots, 5$ and all other variables at the means. As shown in Table 3 , the predicted probability of being in the highest category of support (=5) is 0.43 if economy $=5$ and 0.08 if economy $=4$. Predicted probabilities of being in the middle category of support $(=3)$ is 0.44 if economy $=3$. Predicted probabilities of being in the lowest support category $(=1)$ is 0.24 if economy $=1$. Additional model results and analysis are included in the appendix.

Table 3. Predicted Probabilities with Respect to the Attitude Variable, Economy

\begin{tabular}{cccccc}
\hline Economy & $\boldsymbol{P}(\boldsymbol{y}=\mathbf{5})$ & $\boldsymbol{P}(\boldsymbol{y}=\mathbf{4})$ & $\boldsymbol{P}(\boldsymbol{y}=\mathbf{3})$ & $\boldsymbol{P}(\boldsymbol{y}=\mathbf{2})$ & $\boldsymbol{P}(\boldsymbol{y}=\mathbf{1})$ \\
\hline 1 & 0.0001 & 0.0133 & 0.2453 & 0.4999 & 0.2414 \\
2 & 0.0010 & 0.1092 & 0.6511 & 0.2050 & 0.0336 \\
3 & 0.0089 & 0.5223 & 0.4357 & 0.0293 & 0.0038 \\
4 & 0.0761 & 0.8359 & 0.0843 & 0.0033 & 0.0004 \\
5 & 0.4296 & 0.5600 & 0.0100 & 0.0004 & 0.0000 \\
\hline \multicolumn{5}{r}{ denotes support shellfish aquaculture in Rhode Island waters. }
\end{tabular}

As noted in Section 2.2, the ordinal logistic regression model described in equations (1) through (7) in the appendix is based on the proportional odds assumption. In evaluating the model results, it is necessary to take a closer look at this model property. The score tests of the proportional odds assumption are non-significant $(\mathrm{p}=0.065)$ for Models I and significant $(\mathrm{p}=$ 
0.0029) for Model II. Thus, the proportional odds assumption may not be valid for Model II. However, the test result is not always reliable since the rejection of the proportional odds assumption may occur when the number of explanatory variables is large, as in Model II, or when there is a continuous explanatory variable in the model (Brant 1990; O'Connell 2006). When the result of the proportional odds assumption test is inconclusive, a common approach is to examine the data using a set of separate binary logistic regression equations $(y=0$ or 1$)$ to explicitly see how the odd ratios for our explanatory variables vary at the different thresholds. Table 4 summarizes the results of these binary logit mode estimations. The results provide additional insights into the effects of different explanatory variables on the level of support. For example, shore visibility does not significantly affect the level of support for aquaculture in separate binary specifications. This is not surprising since the shore visibility variable is only marginally significant in Models I and II. Sailing negatively affects only the highest level of support (=5), not lower levels of support (= 4 and 3$)$. Education is affecting high and middle high levels of support (= 4 and 5). Overall, however, the results from separate binary logit models are consistent with those of Models I and II, suggesting that the overall results in Table 2 are robust. 
Table 4. Support of Shellfish Aquaculture: Binary Logit Estimates

\begin{tabular}{|c|c|c|c|}
\hline \multirow[b]{2}{*}{ Variable } & \multicolumn{3}{|c|}{ Coefficient } \\
\hline & $\begin{array}{l}y=1 \text { if } \\
\text { support }=5\end{array}$ & $\begin{array}{l}y=1 \text { if } \\
\text { support }=4,5\end{array}$ & $\begin{array}{l}y=1 \text { if } \\
\text { support }=3,4,5\end{array}$ \\
\hline Intercept & $-16.605^{* * *}$ & $-13.713^{* * *}$ & $-9.094^{* * *}$ \\
\hline Economy & $2.555^{* * *}$ & $2.676^{* * *}$ & $2.652^{* * *}$ \\
\hline Spoil beauty & $-0.739^{* *}$ & $-0.723^{* *}$ & $-0.822^{*}$ \\
\hline Nutrition supply & 0.248 & $0.945^{* *}$ & $3.141^{* * *}$ \\
\hline Interfere use & $-0.735^{* * *}$ & $-1.216^{* * *}$ & -0.610 \\
\hline Important & 0.150 & $0.919^{* *}$ & 0.876 \\
\hline Need more & $1.149^{* * *}$ & 0.538 & $-1.466^{*}$ \\
\hline Shore visible & 0.722 & 0.933 & -0.050 \\
\hline Sailing & $-1.572^{* *}$ & -0.304 & -1.507 \\
\hline Birding & -0.476 & $-3.017^{* * *}$ & -0.727 \\
\hline Biking & 0.699 & $2.344^{* * *}$ & $4.513^{* * *}$ \\
\hline Meeting & 1.445 & $3.232^{*}$ & -2.596 \\
\hline Education & $0.295^{*}$ & $0.409^{* *}$ & -0.259 \\
\hline Observations & 269 & 269 & 269 \\
\hline $\mathrm{R}^{2}$ & 0.759 & 0.775 & 0.803 \\
\hline Likelihood ratio test & $210.76^{* * *}$ & $187.24^{* * *}$ & $118.10^{\text {*** }}$ \\
\hline
\end{tabular}

\section{DISCUSSION \& CONCLUSION}

This study explored public interests associated with aquaculture by analyzing how various factors influence an individual's decision to support or oppose shellfish aquaculture in RI's coastal waters. Findings show that certain attitudinal factors and personal characteristics influence an individual's decision to support aquaculture. Other studies have examined how people think about aquaculture impacts (e.g., D'Anna and Murray 2015; Katranidis et al. 2003), 
yet few have explored the attitude-behavior relationship. An exception is Chu et al. (2010) which showed that aquaculture stakeholders in the US and Norway who thought there were socioeconomic and environmental benefits of aquaculture actively supported aquaculture expansion. Our study found that key attitudinal factors affecting support for aquaculture in RI include attitudes toward shellfish aquaculture's impacts on the local economy, its role as a nutritional food option, its effects on aesthetic quality and its interference with other uses. All of the key attitudes toward aquaculture impacts relate to features of the social system. Attitudes related to shellfish aquaculture's impacts on environmental conditions, like water quality, were not significantly related to support. These findings highlight that support (or opposition) to aquaculture in RI is driven more by attitudes associated with social impacts than by attitudes related to environmental impacts, aligning with findings from a study in New Zealand that showed denials for new marine farms were more often due to social issues than environmental concerns (Banta and Gibbs 2009). More generally, these results emphasize that social and ecological factors influence how people think about and respond to their environment (e.g., Dalton et al 2012). As noted earlier, environmentally-significant behaviors (e.g., decisions to support an aquaculture farm) are affected by different types of causal variables such as attitudinal factors, personal characteristics, and external social and ecological conditions.

To be responsive to the public interests revealed in this study, the RI CRMC should consider using interventions that directly address the primary factors driving support for shellfish aquaculture in RI's coastal waters. For instance, since our findings showed that attitudes related to environmental impacts had no effect on support, hosting environmental education programs that are designed to change attitudes about environmental impacts of aquaculture will not likely affect public support for shellfish aquaculture in RI. More effective strategies for influencing 
support would address attitudes related to aquaculture's negative impacts on other users and aesthetic quality. It would be useful to examine how shellfish aquaculture currently interacts with other uses in RI's coastal waters. To begin to address this issue, the state, through its recent shellfish management planning process, initiated participatory efforts to map aquaculture leases and other uses within its waters (RI CRMC 2014). In addition, Dalton et al. (2015) have begun to explore how coastal users in RI salt ponds think about their interactions with other uses, highlighting that co-occurring uses are not always in conflict. In fact, uses might even benefit from co-occurring in space and time. Further study on the interactions of aquaculture with other uses and what people think about these interactions would improve understanding of how aquaculture interferes with other uses.

Another potential strategy to address key factors shaping support for aquaculture would be to encourage farm design that fits in with Rhode Islanders' conceptions of beauty (also called scenic value or aesthetic quality). However, it is not clear from our findings what beauty actually means to Rhode Islanders. Few academic studies have examined aesthetic quality in relation to aquaculture even though it is recognized as an important consideration in the siting and design of aquaculture sites (for exceptions see Depellegrin 2016; Falconer et al. 2013). A survey of RI recreational boaters indicated that their perceptions of beauty included a combination of cultural features (e.g., traditional cottages, sailboats) and natural features (e.g., sandy beach, vegetation; Dalton and Thompson 2013). Extending this type of study to a broader set of stakeholders and including aquaculture as a cultural feature would provide valuable insights into the cultural, ecological and physical features related to aquaculture that Rhode Islanders think are contributing to aesthetic quality in their coastal waters. 
It is interesting to note that one of the key attitudinal factors affecting support was respondents' attitudes toward aquaculture's role in meeting nutritional needs. Some studies have explored consumer behavior related to aquaculture's role in promoting food security (e.g., Belton et al. 2014; Smith et al. 2015), yet few if any studies have examined how perceived nutritional benefits of farmed seafood influences stakeholder support for farm development. Interventions that focus on perceptions of farmed seafood as a sustainable food source could potentially affect support for farm development. For example, public tours of local shellfish farms could provide information about the nutritional effects of farmed seafood (e.g., Vasta 2015).

Attitudes were not the only factor influencing support for aquaculture in RI's waters. Respondents' personal characteristics also significantly affected support. For instance, model results suggest that respondents who live in homes with a view of RI's coastal waters were more likely than those without views to support aquaculture in RI's coastal waters. These findings indicate that waterview residents in RI are supportive of using coastal waters for aquaculture development; however, that does not mean that they would support a farm they can see from their homes. Individuals who live in homes with waterviews seem supportive of aquaculture in general, but as Dalton et al. (2017) indicate, their support for aquaculture in particular waterbodies declines rapidly as amount of farm development increases. Aquaculture permitting agencies and shellfish farm applicants would benefit from an improved understanding of the amount at which development is no longer acceptable to waterview residents and other stakeholders.

Other personal characteristics were related to an individual's participation in recreational activities. For instance, bicycle riders tend to be supportive of shellfish aquaculture while respondents who participate in sailing and birding are less supportive. This is not surprising as 
individuals who sail or bird are more likely to interact directly with aquaculture activities than individuals cycling along the shoreline, and interference with use was identified as a key attitudinal factor affecting support. While public access is allowed in aquaculture farms in RI (RI CMP 300.11), shallow waters often make it physically impossible for a sailboat to pass through or over a shellfish farm, especially at low tide. Also, local birders have expressed concerns that noise and other farm impacts disrupt bird habitat. Coastal managers could use these findings to initiate dialogue with targeted groups, like sailors and birders, to learn more about their interests and concerns and to share information with them about aquaculture planning and management.

It is not surprising that external conditions did not emerge as a major influence on support for shellfish aquaculture since there was little variation in external conditions in our study. This study focused on one state where the same regulatory scheme applies throughout. The only external condition included in the analysis (respondent's region of residence) was not statistically significant in either of the models. Also, this analysis investigated support for aquaculture in RI's coastal waters in general. Dalton et al. (2017) explores support for different types of aquaculture, showing that farm features, like the type of equipment used on the farm or the size of the farm, will affect support. Future studies could explore how different regulatory regimes and environmental conditions affect support for aquaculture.

Consistent with Stern's (2000) model of factors influencing ESB, we found that a combination of attitudinal factors and personal characteristics influence an individual's support for aquaculture in RI coastal waters. Management strategies designed to influence levels of support should focus efforts on addressing these key drivers. 
By identifying the broader public's interests for shellfish aquaculture in RI, findings from this study and others like it can be used to address public concerns, incorporate public perceptions and attitudes into permitting decisions, and develop outreach targeted at specific stakeholder groups. Such information will reduce unnecessary time and effort spent on proposing and reviewing proposed aquaculture farms that would likely elicit strong negative public reactions and result in lengthy and contentious public processes.

Ethical approval: All procedures performed in this study involving human participants were in accordance with the ethical standards of the institutional and/or national research committee and with the 1964 Helsinki declaration and its later amendments or comparable ethical standards.

Informed consent: Informed consent was obtained from all individual participants included in the study. 


\section{APPENDIX}

\section{Ordinal Logistic Regression Model}

The model is outlined in the context of this study as follows: let $y^{*}$ be a continuous variable representing a respondent's level of support for shellfish aquaculture in RI coastal waters. We do not have specific information on $y^{*}$. The level of support is classified into 5 levels. As a result, $y$ is a latent variable, i.e.,

$$
y^{*}=\beta^{\prime} \mathbf{x}+\varepsilon
$$

where $\mathbf{x}$ is the set of independent variables, $\boldsymbol{\beta}$ is a vector of parameter coefficients to be estimated, and $\varepsilon$ is the error term. Although we do not observe $y^{*}$, we do observe the ordinal response variable $y$ which is positively related to actual level of support for aquaculture $y^{*}$. As mentioned above, in the survey data set, $y$ has five entries.

We have

$$
y=\left\{\begin{array}{cl}
1 & \text { if } y^{*} \leq \mu_{1} \\
2 & \text { if } \mu_{1}<y^{*} \leq \mu_{2} \\
\vdots & \\
5 & \text { if } \mu_{4}<y^{*}
\end{array}\right.
$$

where $\mu_{i}(i=1,2, \ldots, 4)$ are threshold parameters that distinguish the levels of support.

Let $\pi_{i}(\mathbf{x})=P(y=i \mid \mathbf{x})$, the probability of $y=i$, for $i=1,2, \ldots, 5$. The cumulative probabilities for $y \leq i$ are

$$
P(y \leq i \mid \mathbf{x})=\pi_{1}(\mathbf{x})+\cdots+\pi_{i}(\mathbf{x}), \quad i=1, \ldots, 5 .
$$

The cumulative logits (i.e., log odds) are defined as (Agresti 2002)

$$
\begin{aligned}
\operatorname{logit}[P(y \leq i \mid \mathbf{x})]=\log & \frac{P(y \leq i \mid \mathbf{x})}{1-P(y \leq i \mid \mathbf{x})} \\
& =\log \frac{\pi_{1}(\mathbf{x})+\cdots+\pi_{i}(\mathbf{x})}{\pi_{i+1}(\mathbf{x})+\cdots+\pi_{N}(\mathbf{x})}, \quad i=1, \ldots, 4 .
\end{aligned}
$$

The proportional odds model simultaneously uses all cumulative logits is 


$$
\operatorname{logit}[P(y \leq i \mid \mathbf{x})]=\alpha_{i}+\boldsymbol{\beta}^{\prime} \mathbf{x}, \quad i=1, \ldots, 4 .
$$

Each cumulative logit has its own intercept $\left(\alpha_{i}\right)$ which is increasing in $i$.

Predicted probabilities are computed as (Long and Freese 2001):

$$
\begin{aligned}
& P(y=1 \mid \mathbf{x})=\frac{\exp \left(\alpha_{1}+\boldsymbol{\beta}^{\prime} \mathbf{x}\right)}{1+\exp \left(\alpha_{1}+\boldsymbol{\beta}^{\prime} \mathbf{x}\right)^{\prime}} \\
& P(y=i \mid \mathbf{x})=\frac{\exp \left(\alpha_{i}+\boldsymbol{\beta}^{\prime} \mathbf{x}\right)}{1+\exp \left(\alpha_{i}+\boldsymbol{\beta}^{\prime} \mathbf{x}\right)}-\frac{\exp \left(\alpha_{i-1}+\boldsymbol{\beta}^{\prime} \mathbf{x}\right)}{1+\exp \left(\alpha_{i-1}+\boldsymbol{\beta}^{\prime} \mathbf{x}\right)}, \quad i=2, \ldots, 4 \\
& P(y=5 \mid \mathbf{x})=1-\frac{\exp \left(\alpha_{4}+\boldsymbol{\beta}^{\prime} \mathbf{x}\right)}{1+\exp \left(\alpha_{4}+\boldsymbol{\beta}^{\prime} \mathbf{x}\right)} .
\end{aligned}
$$

Since the probabilities modeled are cumulated over the lower ordered values (see Equation (3)), the probability of, say, $y=2$ is

$$
P(y=2 \mid \mathbf{x})=P(y \leq 2 \mid \mathbf{x})-P(y \leq 1 \mid \mathbf{x}) .
$$

\section{$\underline{\text { Results of Odds Ratio Estimates }}$}

Table A1 presents the proportional odds ratios, which are the coefficients in Table 2 exponentiated, and the corresponding 95\% confidence intervals. We see that for a one-unit increase in economy, the odds of high support versus the combined middle and low categories are 9.15 greater (Model I), given that all of the other variables in the model are held constant. Likewise, the odds of the combined middle and high categories versus low is 9.15 times greater. For respondent who participates in bicycle riding, the odds of the high category of support versus the low and middle categories of support are 2.22 times greater (Model I), given that the other variables in the model are held constant. The same increase, 2.22 times, is found between low support and the combined categories of middle and high support due to the proportional odds assumption. 
Table A1. Odds Ratio Estimates

\begin{tabular}{|c|c|c|c|c|c|c|}
\hline \multirow[b]{2}{*}{ Variable } & \multirow{2}{*}{$\begin{array}{c}\text { Model I } \\
\text { Point } \\
\text { Estimate }\end{array}$} & \multicolumn{5}{|c|}{ Model II } \\
\hline & & \multicolumn{2}{|c|}{$\begin{array}{c}\text { 95\% Confidence } \\
\text { Limits }\end{array}$} & \multirow{2}{*}{$\begin{array}{r}\begin{array}{c}\text { Point } \\
\text { Estimate }\end{array} \\
8.558\end{array}$} & \multicolumn{2}{|c|}{$\begin{array}{c}\text { 95\% Confidence } \\
\text { Limits }\end{array}$} \\
\hline Economy & 9.146 & 5.148 & 16.249 & & 4.719 & 15.520 \\
\hline Spoil beauty & 0.520 & 0.377 & 0.716 & 0.548 & 0.392 & 0.765 \\
\hline Nutrition supply & 2.619 & 1.695 & 4.046 & 2.117 & 1.325 & 3.380 \\
\hline Interfere use & 0.596 & 0.430 & 0.826 & 0.579 & 0.410 & 0.816 \\
\hline Important & - & - & - & 1.656 & 1.100 & 2.491 \\
\hline Need more & - & - & - & 1.788 & 1.193 & 2.680 \\
\hline Shore visible & 1.754 & 0.941 & 3.269 & 1.767 & 0.901 & 3.466 \\
\hline Sailing & - & - & - & 0.412 & 0.179 & 0.949 \\
\hline Birding & 0.440 & 0.207 & 0.934 & 0.452 & 0.203 & 1.004 \\
\hline Biking & 2.223 & 1.151 & 4.294 & 2.751 & 1.376 & 5.500 \\
\hline Meeting & - & - & - & 2.740 & 0.886 & 8.473 \\
\hline Education & 1.217 & 0.998 & 1.484 & 1.247 & 1.017 & 1.529 \\
\hline
\end{tabular}




\section{References}

Agresti A (2002) Categorical data analysis. 2nd edn. John Wiley \& Sons, Hoboken, NJ

Aiken L (2002) Definitions, History, and Behavior Prediction. Attitudes and Related

Psychosocial Constructs Theories, Assessment, and Research. Sage Publications, Thousand Oaks, CA

Banta W, Gibbs M (2009) Factors Controlling the Development of the Aquaculture Industry in New Zealand: Legislative Reform and Social Carrying Capacity Coastal Management $37: 170-196$

Belton B, van Asseldonk IJM, Thilsted SH (2014) Faltering fisheries and ascendant aquaculture: Implications for food and nutrition security in Bangladesh Food Policy 44:77-87 doi:10.1016/j.foodpol.2013.11.003

Beutel D (2015) Aquaculture in Rhode Island: 2015 Annual Status Report. RI Coastal Resources Management Council, Wakefield, RI

Birkland T (2001) An Introduction to the Policy Process: Theories, Concepts, and Models of Public Policy Making. M.E. Sharpe Inc., Armonk, NY

Brant R (1990) Assessing proportionality in the proportional odds model for ordinal logistic regression Biometrics 46:1171-1178

Chu JJ, Anderson JL, Asche F, Tudur L (2010) Stakeholders' Perceptions of Aquaculture and Implications for its Future: A Comparison of the USA and Norway Mar Resour Econ 25:61-76

Coleman J (1990) Foundations of social theory. Harvard University Press, Cambridge, MA 
Cranford PJ, Kamermans P, Krause G, Mazurié J, Buck B, Dolmer P, Fraser D, Van

Nieuwenhove K, O’Beirn FX, Sanchez-Mata A, Thorarinsdóttir GG, Strand O (2012) An ecosystem-based approach and management framework for the integrated evaluation of bivalve aquaculture impacts Aquacult Environ Interact 2:193-213

D'Anna LM, Murray GD (2015) Perceptions of shellfish aquaculture in British Columbia and implications for well-being in marine social-ecological systems Ecology and Society 20

Dalton T, Jin D, Thompson R, Katzanek A (2017) Using normative evaluations to plan for and manage shellfish aquaculture development in RI coastal waters Marine Policy 83:194203

Dalton T, Thompson R (2013) Recreational boaters' perceptions of scenic vaue in Rhode Island coastal waters Ocean \& Coastal Management 71:99-107

Dalton T, Thompson R, Patrolia E Understanding perceptions of recreational uses in RI's coastal salt ponds. In: International Congress on Coastal and Marine Tourism, Hawaii, 2015.

Depellegrin D (2016) Assessing cumulative visual impacts in coastal areas of the Baltic Sea Ocean and Coastal Management 119:184-198 doi:10.1016/j.ocecoaman.2015.10.012

Dillman DA, Smyth JD, Christian LM (2009) Internet, mail and mixed mode surveys: the tailored design method. 3rd edn. John Wiley \& Sons, Hoboken, NJ

Falconer L, Hunter DC, Telfer TC, Ross LG (2013) Visual, seascape and landscape analysis to support coastal aquaculture site selection Land Use Policy 34:1-10 doi:10.1016/j.landusepol.2013.02.002

Filgueira, R., Comeau, L.A., Guyondet, T., McKindsey, C.W., Byron, C.J., (2015) Modelling carrying capacity of bivalve aquaculture: a review of definitions and methods, 
Encyclopedia of Sustainability Science and Technology. Springer Science+Business Media, New York

Guagnano GA, Stern PC, Dietz T (1995) Influences on attitude-behavior relationships: a natural experiment with curbside recycling Environment and Behavior 27:699-718

Heberlein TA (2012) Navigating environmental attitudes. Oxford University Press,

Hines JM, Hungerford HR, Tomera AN (1986/87) Analysis and synthesis of research on responsible environmental behavior: a meta-analysis Journal of Environmental Education 18:18

Jin, D, G. DePiper and P. Hoagland. 2016. Applying portfolio management to implement ecosystem-based fishery management. North American Journal of Fisheries Management 36(3):652-669.

Joyce AL, Satterfield TA (2010) Shellfish aquaculture and First Nations' sovereignty: The quest for sustainable development in contested sea space Natural Resources Forum 34:106-123

Kaiser FG, Wolfing S, Fuhrer U (1999) Environmental attitude and ecological behaviour Journal of Environmental Psychology 19:1-19

Katranidis S, Nitsi E, Vakrou A (2003) Social acceptability of Aquaculture development in coastal areas: The case of two Greek islands Coastal Management 31:37-53 doi:10.1080/08920750390168291

Kite-Powell HL, Rubino MC, Morehead B (2013) THE FUTURE OF U.S. SEAFOOD SUPPLY Aquaculture Economics and Management 17:228-250

doi:10.1080/13657305.2013.812691 
Knapp G, Rubino MC (2016) The political economics of marine aquaculture in the United States Reviews in Fisheries Science and Aquaculture 24:213-229 doi:10.1080/23308249.2015.1121202

Kraus SJ (1995) Attitudes and the prediction of behavior: A meta-analysis of the empirical literature Personality and Social Psychology Bulletin 21:58-75

Long JS, Freese J (2001) Regression Models for Categorical Dependent Variables Using Stata. Stata Press, College Station, TX

Mazur NA, Curtis AL (2008) Understanding community perceptions of aquaculture: lessons from Australia Aquaculture International 16:601-621 doi:10.1007/s10499-008-9171-0

Murray G, D'Anna L (2015) Seeing shellfish from the seashore: The importance of values and place in perceptions of aquaculture and marine social-ecological system interactions Marine Policy 62:125-133 doi:10.1016/j.marpol.2015.09.005

National Research Council (NRC) (2005) Decision making for the environment. National Academies Press, Washington, DC

NOAA (2008) Offshore Aquaculture in the United States: Economic Considerations, Implications and Opportunities. NOAA, Silver Spring, MD

NOAA (2017) Commercial Fisheries Statistics. Office of Science and Technology, NOAA Fisheries. Silver Spring, MD. 〈http://www.st.nmfs.noaa.gov/commercial-fisheries/index> O'Connell A (2006) Logistic Regression Models for Ordinal Response Variables. Sage Publications, Thousand Oaks, CA

Olli E, Grendstad G, Wollebaek D (2001) Correlates of environmental behaviors: Bringing Back Social Context Environment and Behavior 33:181 
Ostrom E (1990) Governing the commons: the evolution of institutions for collective action. Cambridge University Press, Cambridge, UK

RI Coastal Management Program (CMP), 300.11(D).

RI Coastal Resources Management Council (2014) Rhode Island Shellfish Management Plan.

RI General Laws. Title 20: Fish and Wildlife. Chapter 20-10: Aquaculture

Schultz PW (2011) Conservation Means Behavior Conservation Biology 25:1080-1083 doi:10.1111/j.1523-1739.2011.01766.x

Shafer CS, Inglis GJ, Martin V (2010) Examining Residents' Proximity, Recreational Use, and Perceptions Regarding Proposed Aquaculture Development Coastal Management 38:559574 doi:10.1080/08920753.2010.511700

Silver JJ (2013) Neoliberalizing coastal space and subjects: On shellfish aquaculture projections, interventions and outcomes in British Columbia, Canada Journal of Rural Studies 32:430438 doi:10.1016/j.jrurstud.2013.10.003

Silver JJ (2014) From fishing to farming: Shellfish aquaculture expansion and the complexities of ocean space on Canada's west coast Applied Geography 54:110-117 doi:10.1016/j.apgeog.2014.07.013

Smith S, Varble S, S. S (2015) Fish Consumers: Environmental Attitudes and Purchasing Behavior Journal of Food Products Marketing:1-17

Steel B (1996) Thinking globally and acting locally?: Environmental attitudes, behavior and activism Journal of Environmental Management 47:27-36 
Steg L, Dreijerink L, Abrahamse W (2005) Factors influencing the acceptability of energy policies: a test of VBN theory Journal of Environmental Psychology 25:415-425

Stern PC (2000) Toward a coherent theory of environmentally significant behavior J Soc Issues 56:407-424 doi:10.1111/0022-4537.00175

Stern PC, Dietz T (1994) The value basis of environmental concern J Soc Issues 50:65-84

Stern PC, Dietz T, Kalof L, Guagnano GA (1995) Values, beliefs, and proenvironmental action attitude formation toward emergent attitude objects J Appl Soc Psychol 25:1611-1636 doi:10.1111/j.1559-1816.1995.tb02636.x

Vaske JJ (2008) Survey research and analysis: Applications in parks, recreation, and human dimensions. Venture Publishing, State College, PA

Vaske JJ, Donnelly MP (1999) A value-attitude-behavior model predicting wildland preservation voting intentions Society \& Natural Resources 12:523-537 doi:10.1080/089419299279425

Vasta M (2015) Shellfish farms as agritourism destinations: the growers' perspective. MA Thesis, Marine Affairs University of Rhode Island

Voyer M, Gladstone W, Goodall H (2012) Methods of social assessment in Marine Protected Area planning: Is public participation enough? Marine Policy 36:432-439 doi:10.1016/j.marpol.2011.08.002

Whitmarsh D, Palmieri MG (2009) Social acceptability of marine aquaculture: The use of survey-based methods for eliciting public and stakeholder preferences Marine Policy 33:452-457 doi:10.1016/j.marpol.2008.10.003 
Wilson C, Dowlatabadi H (2007) Models of decision making and residential energy use. In: Annual Review of Environment and Resources, vol 32. Annual Review of Environment and Resources. Annual Reviews, Palo Alto, pp 169-203. doi:10.1146/annurev.energy.32.053006.141137 